\title{
AIDS E A ESCOLA: PROPOSTA INTERDISCIPLINAR E INSTITUCIONAL DE PREVENÇÃO
}

\author{
AIDS AND SCHOOL, INSTITUTIONAL AND INTERDISCIPLINARY PREVENTION \\ PROPOSAL \\ SIDA Y LA ESCUELA: PROPUESTA INTERDISCIPLINAR E INSTITUCIONAL DE
PREVENCIÓN
} Regina de Oliveira Carvalho ${ }^{1}$

\begin{abstract}
RESUMO : O Projeto AIDS E A ESCOLA surge como uma proposta interdisciplinar e institucional de combate ao HIV / AIDS. Em 1992, a Universidade do Estado do Rio de Janeiro, representada pelas Faculdades de Enfermagem e Serviço Social e pelo Núcleo de Estudos de Saúde do Adolescente e as Secretarias de Estado de Saúde e de Educação, e ainda a FIO-CRUZ, pensaram uma forma de intervir preventivamente na faixa etária em que mais se expressava o contato com o virus. O adolescente deveria ser trabalhado, mas, para alcançar um grande número, nada melhor que o professor para isso. A partir daí, o projeto foi escrito e seu desenvolvimento iniciou-se, em 1994, com a capacitação de professores de $1^{\circ}$ e $2^{\circ}$ Graus de seis Municípios do Estado do Rio de Janeiro. O trabalho é de relevância pela sua caracteristica de supervisão e apoio do GEPAE (Grupo Executivo do Projeto AIDS e a Escola). Nas oficinas, são trabalhados com os professores os temas: Perda e Morte; Sexualidade; Sexualidade em Tempo de AIDS; Informação Técnica e Metodologias Aplicadas. O Projeto é financiado pelo Banco Mundial através do Ministério de Saúde. Atualmente, estamos realizando avaliação do Projeto e já detectamos que, pela sua performance e caracteristicas, se tornará um Programa.
\end{abstract}

UNITERMAS. Prevencãn-Adalescência - AlnS - Fnfermagem

ABSTRACT: The project AIDS and School emerges as an institutional and interdisciplinary new proposal for HIV / AIDS combat. In 1992, Rio de Janeiro State University represented by Social Work and Nursing Faculties and by Adolescent Health Studies Nucleus and Education and Health State Secretaries and yet Oswaldo Cruz Foundation ( $\mathrm{FlO}-\mathrm{CRUZ}$ ), thought about a way of preventively intervene with the age where the contact with the virus is mostly contacted. The adolescent should be worked on but for achieving a great number of students, a teacher was needed. From this, the project was designed and its development started in 1994 with ' $1{ }^{\circ}$ and $2^{\circ}$ graus' teachers capacitation in six districts of Rio de Janeiro. The work is of relevance for its supervision characteristics and support to GEPAE (AIDS and School Project Executive Group). At the workshops themes are worked with the teachers, such as: Loss and Death; Sexuality: Sexuality in AIDS times: Technical Information and Applied Methodology. This project is sponsored by the World Bank through Health Ministry. Nowadays, we are evaluating the project and we have already detected that for its performance and characteristics it will be turned into a Programme.

KEYWORDS: Prevention - Adolescence - AIDS - Nursing.

\footnotetext{
${ }^{1}$ Professora do Dept $^{\circ}$ de Enfermagem Médico-Cirúrgica da Faculdade de Enfermagem da UERJ, Mestranda em Saúde Pública - CCBS /UNI-RIO.
} 
RESUMEN : EI Proyecto SIDA Y LA ESCUELA aparece como una propuesta interdisciplinar e institucional de combate al HIV /SIDA. En 1992, la Universidad del Estado de Rio de Janeiro representada por las Facultades de Enfermeria y Servicio Social y por el Núcleo de Estudios de Salud del Adolescente y las Secretarias de Estado de Salud y de Educación, y también la FIO-CRUZ, pensaron una forma de intervenir preventivamente en la faja de edad en que mas se manifestaba el contacto con el vírus. El adolescente debería ser trabajado, pero, para alcanzar un gran número, nada mejor que el profesor para eso. A partir de ahi, el proyecto fué escrito y su desarrollo se inició en 1994, con la capacitación de profesores de 10 y $2^{\circ}$ de seis municipios del Estado de Rio de Janeiro. El trabajo es de relevancia por su característica de supervisión y apoyo del GEPAE (Grupo Ejecutivo del Proyecto AIDS y la Escuela). En los laboratorios son trabajados con los profesores los temas: Pérdida y Muerte; Sexualidad; Sexualidad en tiempo de SIDA; Información Técnica y Metodologías Aplicadas. El proyecto es financiado por el Banco Mundial por medio del Ministerio de Salud. Actualmente estamos realizando evaluación del Proyecto y ya detectamos que por su desempeño y caracteristicas se tornará un programa.

UNITÉRMINOS: Prevención-Adolescencia - SIDA - Enfermería.

\section{RELATO DE UMA EXPERIÊNCIA INTERDISCIPLINAR E INSTITUCIONAL}

\section{BREVE APRESENTAÇÃO}

O Projeto AIDS e a Escola (P. A. E.) nasceu da discussão entre os órgãos normalizadores da Educação e da Saúde do Rio de Janeiro com a Academia.

Inicialmente, a Secretaria de Estado de Educação do Rio de Janeiro participou do Projeto (1992-1993), mas como suas perspectivas de ação não coincidiam com a das outras entidades, representadas no P.A.E., o Projeto prosseguiu sem a referida Secretaria. Em 1994, houve a decolagem das atividades, que culminou com a capacitação de seis Municipios do Rio de Janeiro.

A interdisciplinaridade é constatada pelas categorias profissionais que representam as instituições. Da Secretaria de Estado de Saúde, há duas representações setoriais: uma médica e duas assistentes sociais da Divisão de DST / AIDS, uma enfermeira e uma assistente social da Assessoria de Educação em Saúde. Da Universidade do Estado do Rio de Janeiro, há três representações de unidades universitárias: uma professora da Faculdade de Enfermagem, que coordena o projeto dentro da UERJ; uma professora da Faculdade de Serviço Social; uma psicóloga e uma assistente social que representam o NESA (Núcleo de Estudos da Saúde do Adolescente) do Hospital Universitário Pedro Ernesto. Da FIO-CRUZ (Fundação Instituto Oswaldo Cruz), há uma representação que, até o momento, era feita por um biólogo do laboratório de controle de Saúde Ambiental. 
No GEPAE (Grupo Executivo do Projeto AIDS e a Escola), descrito em sua composição no parágrafo anterior, soma-se os bolsistas de Extensão, que são alunos da UERJ e que podem representar suas Faculdades. O Projeto recebe ainda residentes de Medicina que estejam estagiando no NESA para perceberem, ainda que superficialmente, as atividades do P.A.E., como proposta interdisciplinar e institucional de prevenção do HIV / AIDS.

Ocorrem encontros semanais, onde cada representante dispõe de dez horas de sua carga horária para que sejam discutidos, planejados e avaliados todos os passos do P.A.E., bem como estudar conteúdos e discutir novas metodologias para a realização de oficinas.

\section{AÇÕES DESENVOLVIDAS}

À medida que a AIDS entra no cenário de uma epidemia que foge do controle da Saúde Pública, que traz na sua trajetória milhares de vítimas na faixa etária entre 20 e 35 anos, esforços são empreendidos para que se consiga enfrentar um inimigo tão cruel porque, em cima de tabus e preconceitos, o vírus se espalha. Os jovens entre 15 e 18 anos são os mais expostos ao risco, a partir do momento que o adolescente não tem a compreensão de todas as mudanças e das conseqüências indesejáveis que podem advir de uma curiosidade que naturalmente emana de seu corpo, de sua relação com o mundo.

Trabalhar a sexualidade, desvelando o que é velado, desnudando o que é coberto e socializando o que é colocado como segredo, impróprio e pecado, é uma das oficinas propostas na capacitação. Se os professores não estiverem preparados para ouvir, discutir, dialogar, entender o que se passa com ele mesmo em relação ao mundo que o cerca; se o professor não souber lidar com a erotização, com a sedução como fenômenos naturais nas relações interpessoais, inclusive quando se lida com o desejo e o prazer; se lhe falta a compreensão de que viver é a forma mais prazerosa de lidar com a natureza e com o mundo, muito vai the faltar para falar de sexualidade com seus alunos. $\mathrm{Na}$ oficina que se realiza, tenta-se resgatar esta compreensão com os professores.

Discutir sexualidade e AIDS na Escola é discutir o papel desta instituição em sua concepção pedagógica, é discutir de que forma ela deve relacionar-se com o mundo, com o outro e com a comunidade.

Não basta distribuir conselhos através de folders, de passar filmes ou transmitir conhecimento de como o virus entra e age no organismo humano porque está comprovado, em uma década de epidemia, que isto não funciona. Sensibilizar professores, diretores, Secretários de Educação quanto a isso é a nossa tarefa, como é também capacitá-los para desenvolver metodologias de trabalho que multipliquem esforços na direção certa. 
A tarefa árdua é responder à altura ao desafio que a AIDS traz, principalmente não subestimando o risco que convive com ela, mantendo o interesse na vida, no prazer, no erotismo, na sedução, no amor e na convivência.

Questionar a capacidade das pessoas quanto à apreensão de que a epidemia da AIDS é algo concreto e próximo da humanidade e propiciar formas de compreensão é uma das tarefas do P.A.E.

O P.A.E. é financiado pelo Banco Mundial, através do Ministério da Saúde, e a gestão financeira é realizada pela Secretaria de Estado de Saúde do Rio de Janeiro, sendo também ai localizada a sede do GEPAE.

Manter canal aberto para comunicação constante entre os multiplicadores, os núcleos e o GEPAE e sustentar atualização continua é uma das condições para que a experiência dê certo.

Alguns pressupostos devem ser perseguidos, como, por exemplo:

a) discutir que o medo e o risco andam juntos;

b) as concepções errôneas a respeito da sexualidade e da AIDS oferecem grande resistência no enfrentamento do problema;

c) que até o ano 2000 , alguém muito próximo a nós estará soropositivo.

A partir da tomada de consciência destes fatos, são trabalhados os temas: sexualidade; sexualidade em tempos de AIDS; preconceito; perdas; convivência com o HIV / AIDS; informações técnicas e metodologias aplicadas.

Recuperar a essência do ser, sua relação com a vida e com o outro e tudo que emana dele é uma das práticas que exige o esforço e a atenção para os aspectos filosóficos, politicos, sociais, culturais e até de poder contextualizados na comunidade.

As formas de ver o mundo, a consciência de si, do outro e do mundo são consideradas também na capacitação dos educadores. A possibilidade de promover ação-transformação é que motiva o GEPAE na caminhada do PROJETO.

\section{TEMAS DA OFICINA}

- PERDA E MORTE

Objetivos:

- Dissociar a representação de AIDS com a morte;

- Historiar a construção social desta associação;

- Refletir as implicações desta associação para o trabalho de prevenção. 


\section{- CONVIVÊNCIA COM A PESSOA COM HIV I AIDS NA COMUNIDADE} ESCOLAR

Objetivos:

- Concretizar uma situação de convivio do HIV na escola;

- Levantar as dificuldades, fantasias e outras questões em relação a este tema;

- Verificar a existência do estereótipo em relação à pessoa com HIVIAIDS;

- Apontar e desmitificar a noção de grupo de risco;

- Desenvolver comportamentos solidários em relação à pessoa com HIV / AIDS;

- Inserir a questão da cidadania no enfrentamento da epidemia, enfatizando a necessidade da organização de uma politica em torno desta questão.

\section{- SEXuALIDADE}

Objetivos:

- Levantar o referencial do grupo;

- Apontar que esse referencial é construido social e historicamente;

- Refletir sobre o conceito de gênero, questionando a dimensão biológica que vem determinando atributos culturais para os sexos masculino e feminino;

- Ressaltar o respeito a valores sexuais diferentes;

- Destacar a importância do acesso à informação, esta entendida como um direito à vida;

- Levantar com o grupo o papel da escola com relação à questão da sexualidade.

\section{- SEXuALIDADE NOS TEMPOS DA AIDS}

\section{Objetivos:}

- Levantar o referencial do grupo em relação a esta questão;

- Comparar este referencial com o de sexualidade;

- Refletir sobre a capacidade de tomar decisões e ser responsável por elas ao se envolver em relacionamentos sexuais;

- Reconhecer e respeitar as práticas sexuais prazerosas e seguras conhecidas pelo grupo;

- Levantar as possiveis dificuldades para vivenciar estas práticas sexuais nos tempos da AIDS;

- Verificar como este tema pode ser desenvolvido na escola.

\section{- INFORMAÇÃO TÉCNICA}

\section{Objetivos:}

- Levantar as informações do grupo sobre o tema;

- Repassar os conhecimentos sobre a doença, origem, transmissão e tratamento. 


\section{- METODOLOgIA}

Objetivos:

- Ressaltar o papel que se atribui ao educador e educando no desenvolvimento do trabalho;

- Elaborar uma proposta educativa, tendo como eixo os recursos existentes;

- Discutir a importância da opção metodológica na construção da proposta de trabalho.

\section{ACORDOS E PARCERIAS}

Para a efetivação das oficinas, deve-se estabelecer um acordo que resguarda os passos e as responsabilidades de cada uma das partes, GEPAE e Secretaria Municipal de Educação.

Deixar claro que o P.A.E. não é um projeto solidário, mas sim que pressupõe intervenção ainda que seja restritiva a núcleos que são criados a partir das oficinas de capacitação; isto se faz necessário para que politicamente sejam efetivadas as ações do Núcleo e não fiquem a mercê de pessoas e cargos.

Apoio material costuma ser o esperado do Municipio e o senso compartilhado de comunidade, grupos, associações pode ser o desejado para a ampliação do trabalho preventivo naquele Municipio.

\section{AVALIAÇÃO DO PROJETO}

No momento, o P.A.E. está passando por uma avaliação e para tal há um avaliador externo que com o grupo traçou as diretrizes gerais do Projeto, seu alcance, sua resposta e sinalizou sobre a caracterização deste como Programa, já que em cada Municipio trabalhado um Núcleo Municipal é referendado pelos educadores que participaram das oficinas e pela Secretaria Municipal de Educação, não se prevendo seu término.

O P. A. E. não é pontual; ocorrem supervisões trimestrais que têm objetivo de apoiar o trabalho dos Núcleos na sua dimensão pedagógica e de multiplicar as propostas e ampliar o raio de ação das questões relativas à sexualidade e a prevenção da AIDS nas Escolas.

\section{ATIVIDADES REALIZADAS}

- Levantamento de material educativo referente à sexualidade e prevenção de DST / AIDS;

- Realização da I oficina de sensibilização;

- Aplicação de questionário junto a 363 alunos da rede pública estadual e municipal para diagnosticar o conhecimento dos jovens em relação a DST / AIDS e sua prevenção; 
- Realização de sete oficinas de capacitação, sendo:

- duas para os professores da Rede Estadual do Municipio do Rio de Janeiro;

- uma para os professores da Rede Municipal do Municipio do Rio de Janeiro;

- uma para os professores do Municipio de Itaguai;

- uma para os professores do Municipio de Saquarema;

- uma para os professores do Municipio de Angra dos Reis;

- uma para os professores do Municipio de Rio das Ostras; e

- uma para os professores do Municipio de Resende.

- Produção de Boletins Informativos trimestrais que são distribuídos para todas as escolas trabalhadas e em algumas Secretarias da Saúde;

- Realização de dois Seminários Estaduais, um em 1994 e outro em 1995. com a presença de aproximadamente 200 professores em cada um deles;

- Supervisão das atividades desenvolvidas nos Núcleos Municipais a cada três meses;

- Campo de atuação para Bolsistas de Extensão, que desenvolvem ações e percepçōes de um trabalho interdisciplinar e institucional;

- Confecção de um Caderno de Experiências sobre o desenvolvimento do Projeto com seus temas, discussões e conclusões;

- Estudo integrado com bolsistas e integrantes do P.A.E. sobre os temas discutidos e outros transversais ao tema;

- Jogos, camisinhas, "folders", cartazes são oferecidos nas escolas e Municipios objetos do treinamento.

\section{INDICAÇÕES PARA LEITURA}

ZAGURY, Tânia. O Adolescente por Ele Mesmo - orientação para pais e educadores. 3.ed. Rio de Janeiro: Record. 1996. Record. 1993.

Educar sem culpa, a gênese da ética. Rio de Janeiro:

CHAUI, Marilena. Repressão Sexual, Essa Nossa (Des) Conhecida. São Paulo: Brasiliense. 1984.

FOUCAULT, Michel. História da Sexualidade 1 a vontade de saber, 2 o uso dos prazeres, 3 o cuidado de si. Rio de Janeiro: Graal. 1988.

PAZ, Otávio. A Dupla Chama Amor e Erotismo. São Paulo: Ciciliano. 1994. 
CATONNÉ, Jean-Philippe. A sexualidade, ontem e hoje. São Paulo: Cortez. 1994.

AMÂNCIO, Ligia. Masculino e Feminino - A Construção Social da Diferença. Porto, Afrontamento. 1994.

\section{FILMES RECOMENDADOS}

- Como Água para Chocolate

- O Cheiro da Papaia Verde

- Morango com Chocolate

- A História de Ryan White.

- Irmãos de Sangue

\section{BIBLIOGRAFIA}

1. ALTMAN, Dennis. Poder e Comunidade - Respostas Organizacionais e culturais à AIDS. Rio de Janeiro: Relume-Dumará; ABIA/IMS - UERJ. 1995.

2. BIRMAN, Joel. A sexualidade entre o mal e as maledicências. In: AIDS e Sexualidade: o ponto de vista das ciências humanas. Rio de Janeiro: Relume-Dumará; UERJ. 1994

3. FREIRE, Jurandir. AIDS no Brasil. Rio de Janeiro: Relume-Dumará; IMS UERJ. 1994

4. LOYOLA, M. ${ }^{a}$ (org. ). AIDS e sexualidade: o ponto de vista das ciências humanas. Rio de Janeiro: Relume-Dumará; UERJ. 1994 